\title{
IMPACT OF THE WIND LOAD PROBABILITY DISTRIBUTION AND CONNECTION TYPES ON THE RELIABILITY INDEX OF TRUSS TOWERS
}

\author{
Wojciech Mochocki, Paulina Obara, Urszula Radoń \\ Kielce University of Technology, Faculty of Civil Engineering and Architecture, Kielce, Poland \\ e-mail:wmochocki@tu.kielce.pl; paula@tu.kielce.pl; zmbur@tu.kielce.pl
}

\begin{abstract}
The paper concerns the analysis of reliability of three truss towers performed with the system approach. The first stage of the reliability analysis involved determination of the reliability index for trusses while assuming the same reliability of elements. In the second stage, assessment of the reliability was made according to Eurocodes. The impact of the wind load probability distribution and connection types in towers on their reliability was analysed. In the capacity function, the following random variables were taken into account: cross-sectional area, yield strength, modulus of elasticity, minimum moment of inertia, and length of the element.
\end{abstract}

Keywords: steel truss towers, load distribution, system approach, reliability index

\section{Introduction}

Steel truss towers are pin-jointed multi-element self-supporting structures. Towers are characterized by being rigidly fixed to the base. The towers come in a variety of types, the classification is based, among others, on use (Rykaluk, 2005). In many cases, steel truss towers provide the best structural option due to many factors, including low material consumption and a simple erection process. In the design of such structures, reliability assessment is an issue of key importance. The overall level of safety is largely determined by interaction of structural elements in the load-carrying system, and by safety of individual elements. The issues related to truss tower failure have been discussed in many papers (Błaszczyński et al., 2014; Paczkowska and Paczkowski, 2013; Skwarek et al., 2013; Skwarek and Hulimka, 2011; Davies, 2011).

The reliability analysis of truss structures has been dealt with by many researchers. Four groups of methods can be used for assessing the reliability of a structure: I level (semi-probabilistic) methods, II level (approximation and simulation) methods, III level (fully probabilistic) methods and the system approach (serial, parallel and mixed systems). In each of the methods, a reliability index (Woliński and Wróbel, 2001) is usually employed as a measure of the overall structural reliability. In (Kamiński and Szafran, 2010), the reliability index of a steel telecommunication truss tower was determined using a generalized stochastic perturbation method and the response function technique. In (Dudzik, 2017), the reliability index for an aluminium truss was determined with the FORM approximation method, and also the Monte Carlo and Importance Sampling simulation methods. The reliability index of an aluminium truss tower was also determined in (Winkelmann and Oziębło, 2015). The authors used three different probabilistic methods: the Monte Carlo method, the Point Estimate method and the Response Surface Method. Of all the reliability methods, the system approach is definitely the most comprehensive one. The system approach includes both determination of reliability models and reliability analysis. This type of the reliability analysis was used, among others, in (Biegus, 1977; Thoft-Christensen and Baker, 1982; Woliński and Wróbel, 2001; Park et al., 2004; 
Kłosowska et al., 2017; Kubicka et al., 2019; Mochocki et al., 2018a,b; Mochocki and Radon, 2019).

In addition to the choice of the reliability analysis method, it is very important to assign the right type of the probability distribution to the right types of loads. The distribution of the maximum (or minimum) values is adequate for variable loads such as wind, snow and ice. To describe some random variables, it is necessary to determine the distribution of extreme values, e.g. extreme wind load in a given time period. The most often used extreme value distributions include the Gumbel, the Weibull and the Frechet distributions (Gwóźdź and Machowski, 2011; Śniady, 2000; Murzewski, 1999; Nowak and Collins, 2000). To carry out the reliability analysis, it is necessary to replace a given distribution with another one having required characteristics. For approximation of the distributions, the following are most commonly applied: the Method of Moments and the Point Collocation Method (Gwóźdź and Machowski, 2011).

The paper reports the reliability analysis of steel truss towers, in which the system approach was employed. Three types of towers with different topology were discussed. Reliability models were determined for these structures, and next the reliability analysis was carried out. Two types of load distribution (normal and Gumbel) were used. In calculations, due to the transformation from extreme to normal distribution, two approximation methods were applied, namely the Method of Moments and the Point Collocation Method.

\section{Materials and methods}

In the paper, the system approach was used to analyse the reliability of steel truss towers. This method takes into account interaction of individual elements of the whole structure in the load-carrying system. The system approach consists of two stages. In the first stage, a reliability model is defined, and in the second - the reliability index is calculated.

\subsection{Reliability model}

To define the reliability model, which is the structure eigenvalue, kinematically admissible failure mechanisms (KAFMs), which contain minimal critical sets of elements (MCSEs), are specified. Failure of all elements included in the MCSE leads to transformation of the safe structural system into a mechanism - a system of incomplete fixity. To determine the reliability model, spectral analysis (Kłosowska et al., 2017; Mochocki et al., 2018b) of the linear stiffness matrix was used

$$
\left(\mathbf{K}_{L}-\lambda \mathbf{I}\right) \mathbf{q}=\mathbf{0}
$$

where $\mathbf{K}_{L}$ is the linear stiffness matrix, $\lambda$ is the eigenvalue and $\mathbf{q}$ is the displacement vector. To identify all possible non-repeatable combinations of removed rods transforming the truss into a mechanism, a program based on the application of the Finite Element Method was created.

\subsection{Reliability of the system}

The reliability analysis of the system leads to calculation of the reliability index $\beta$, which is a measure of safety. The reliability index depends on the reliability of the system $R$, which is determined for each reliability model applied. For the trusses of concern, three types of reliability models were obtained, i.e. the serial system, the parallel-serial system and the serial-parallel system (Fig. 1). The reliability $R$ of these models was calculated as follows:

- for the serial system

$$
R=\prod_{i=1}^{k} R_{i}
$$


— for the parallel-serial system

$$
R=\prod_{j=1}^{m}\left[1-\prod_{i=1}^{k}\left(1-R_{j i}\right)\right]
$$

— for the serial-parallel system

$$
R=1-\prod_{i=1}^{k}\left(1-\prod_{j=1}^{m} R_{j i}\right)
$$

After calculating the reliability of the system, the reliability index was obtained as

$$
\beta=-\Phi^{-1}(1-R)
$$

where $\Phi$ is the Laplace function.

(a) $-\frac{1}{R_{1}}+\underset{R_{2}}{-2}+\underset{R_{3}}{-3}+\underset{R_{i}}{-i}+\frac{+k}{R_{k}} \quad k \operatorname{MCSE}(l=1)$

(b)

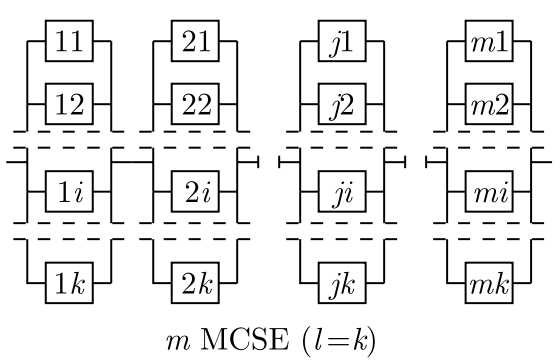

(c)

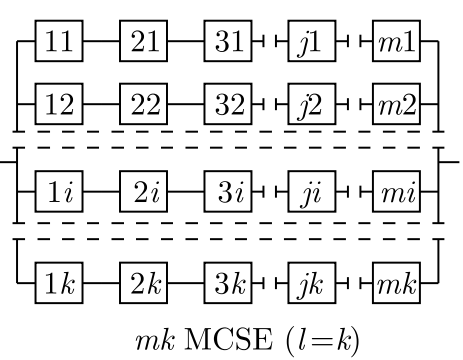

Fig. 1. Types of reliability models: (a) serial system, (b) parallel-serial system, (c) serial-parallel system

The reliability of system (2.2)-(2.4) depends on the reliability of individual elements $R_{i}$ (or $R_{j i}$ ), and on the number of system elements $k, m$ or $m k$ (Kubicka et al., 2019; Mochocki et al., 2018a,b; Mochocki and Radon, 2019). The first step in the determination of reliability of individual elements $R_{i}$ is to determine the expected value $\mu$, standard deviation $\sigma$ of the load effect $E_{i}\left(\mu_{E_{i}}, \sigma_{E_{i}}\right)$ and capacity $N_{i}\left(\mu_{N_{i}}, \sigma_{N_{i}}\right)$. This is the main part of the reliability analysis. The way of calculating these parameters is described in Sections 2.2.1 and 2.2.2, respectively. After computing the load effect and capacity, the standard deviation $\sigma_{Z_{i}}$ and the expected value $\mu_{Z_{i}}$ of the safety margin $Z_{i}$ were calculated

$$
\sigma_{Z_{i}}=\sqrt{\sigma_{N_{i}}^{2}+\sigma_{E_{i}}^{2}} \quad \mu_{Z_{i}}=\mu_{N_{i}}-\mu_{E_{i}}
$$

Finally, the reliability index $\beta_{i}$, and next the reliability $R_{i}$ of a single element were estimated from the following formulas

$$
\beta_{i}=\frac{\mu_{Z_{i}}}{\sigma_{Z_{i}}} \quad R_{i}=1-\Phi\left(-\beta_{i}\right)
$$

\subsubsection{Effect of action}

The expected value $\mu_{E_{i}}$ and standard deviation $\sigma_{E_{i}}$ (first and second probabilistic moments) of the load effect $E_{i}$ depend on the applied probability distribution of a random variable. To describe the behaviour of random variables representing structure loads only a few probability distributions can be used, e.g.: the normal (Gaussian), the log-normal, the Gumbel, the Weibull 
and the Frechet distributions (Gwóźdź and Machowski, 2011; Śniady, 2000; Murzewski, 1999; Nowak and Collins, 2000).

In the paper, the analysed towers were designed according to the standards (PN-EN 1990:2004; PN-EN 1991-1-4; PN-EN 1993-1-1; PN-EN 1993-3-1). The main loads on these structures were the permanent load (self-weight), and also the wind load. Probability distributions for the wind load and for the permanent load differed significantly. To describe the permanent load, the normal distribution was used. As regards wind, the nature of load needs be taken into account. The wind load is idealized as a random (stochastic) process. In calculations, it is necessary to take into account the estimated lifetime of buildings. The characteristic wind load is determined from basic values of wind velocity or wind pressure. These values are identified based on long-term measurements taken by weather stations. In the measurement dataset, it is possible to find values that occurred the most often and very rarely. These empirical data can be approximated by a probability distribution. The best model used to describe the behaviour of wind load are the Gumbel, and Frechet and Weibull distributions. In the paper, the Gumbel distribution was applied.

(a)

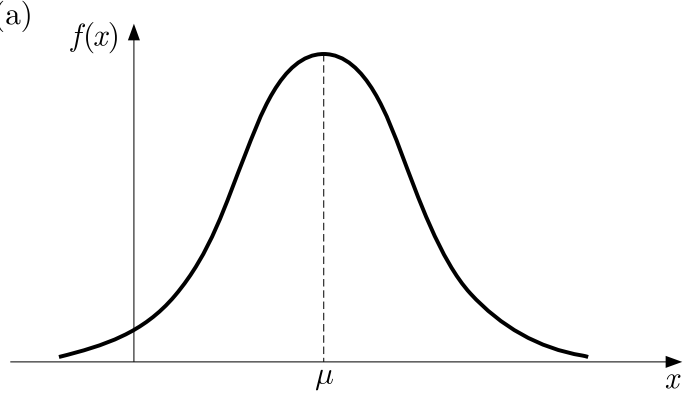

(b)

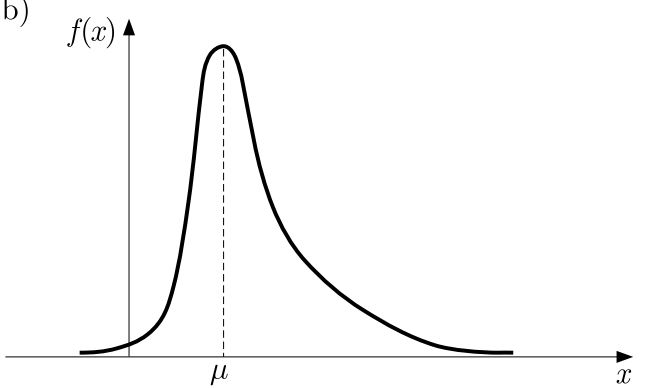

Fig. 2. Probability density function: (a) normal distribution, (b) Gumbel distribution

The normal distribution is characterized by the following density function

$$
f(x)=\frac{1}{\sigma \sqrt{2 \pi}} \exp \left[-\frac{1}{2}\left(\frac{x-\mu}{\sigma}\right)^{2}\right] \quad x \in(-\infty, \infty)
$$

an example of which is shown in Fig. 2a. Function (2.8) is defined by two parameters, namely by the mean value

$$
\mu=\int_{-\infty}^{\infty} x f(x) d x
$$

and by the variance

$$
\sigma^{2}=\int_{-\infty}^{\infty}(x-\mu)^{2} f(x) d x
$$

The Gumbel distribution is characterized by the following density function (Fig. 2b)

$$
f(x)=\alpha \exp \{-\alpha(x-u)-\exp [-\alpha(x-u)]\} \quad x \in(-\infty, \infty)
$$

where $\alpha, u$ are parameters of the Gumbel distribution. The mean value and standard deviation are equal: $\mu=u+0.5772 / \alpha$ and $\sigma=\pi / 2.4495 \alpha$, respectively.

The method of the reliability analysis selected for the paper required that the normal distribution should be used for all random variables. That made it necessary to transform the Gumbel distribution into the normal distribution. To achieve that, two approximation methods, 
namely the Method of Moments and the Point Collocation Method were used (Murzewski, 1989; Gwóźdź and Machowski, 2011).

As regards the two-parameter distributions employed in the paper, the method of probabilistic moments is based on the use of conformity conditions of the mean value and the variance. For the two-parameter distributions $A$ and $B$, from the conformity conditions of the mean value and the variance, the following equations were developed

$$
\int_{-\infty}^{\infty} x f_{A}(x) d x=\int_{-\infty}^{\infty} x f_{B}(x) d x \quad \int_{-\infty}^{\infty}\left(x-\mu_{A}\right)^{2} f_{A}(x) d x=\int_{-\infty}^{\infty}\left(x-\mu_{B}\right)^{2} f_{B}(x) d x
$$

To increase accuracy of calculations, the Point Collocation Method can be used. This method is based on the comparison of the cumulative distribution $F(x)$ and the probability density $f(x)$ at a properly selected collocation point $x_{d}$, which can be expressed by the following formulas

$$
f_{A}\left(x_{d}\right)=f_{B}\left(x_{d}\right) \quad F_{A}\left(x_{d}\right)=F_{B}\left(x_{d}\right)
$$

This method can be used for any two-parameter distributions $A$ and $B$ for two types of the collocation point $x_{d}$, i.e. collocation at the central point and collocation at the limit point. In the paper, the location of the collocation point defines the parameter $k$. It specifies the probability that the realization of $x_{d}$ of the variable $X$ will not be exceeded with the probability $k$. A special type of the Point Collocation Method is the approach in which the approximating distribution is always a normal distribution (Rackwitz and Flessler, 1978). This approach is used in the paper. The relationships between the parameters of the approximating and approximated distribution have the following form

$$
\frac{1}{\mu_{x}} \varphi\left(\frac{x_{d}-\mu_{x}}{\sigma_{x}}\right)=f_{B}\left(x_{d}\right) \quad \Phi\left(\frac{x_{d}-\mu_{x}}{\sigma_{x}}\right)=F_{B}\left(x_{d}\right)
$$

where $\varphi$ is the function of the normal standard distribution.

An alternative to the presented analytical methods is provided by the graphical method based on the use of probabilistic grids (Gwóźdź and Machowski, 2011; Nowak and Collins, 2000).

\subsubsection{Effect of capacity}

The expected value $\mu_{N_{i}}$ and standard deviation $\sigma_{N_{i}}$ of the effect of capacity $N_{i}$ depend on whether the element is in tension or compression. Generally, the standard deviation of the capacity is a function of some random variables (Bołotin, 1968; Kubicka and Radoń, 2018)

$$
\sigma_{N_{i}} \approx \sqrt{\sum_{i=1}^{n}\left(\frac{\partial f}{\partial X_{i}}\right)^{2} \sigma_{X_{i}}^{2}}
$$

where $f$ is the function of uncorrelated variables, $X_{i}$ is the single random variable and $n$ is the number of variables. In the case of elements under tension, random variables are the cross-sectional area $A$ and the yield strength $f_{y}$. The coefficients of variation for these variables are $6 \%$ and 8\%, respectively (JCSS, 2001; Gwóźdź and Machowski, 2011). Based on approximation (2.15), the standard deviation of the capacity is written as

$$
\sigma_{N_{t, R d}} \approx \sqrt{\left(\frac{\partial N_{t, R d}}{\partial A}\right)^{2} \sigma_{A}^{2}+\left(\frac{\partial N_{t, R d}}{\partial f_{y}}\right)^{2} \sigma_{f_{y}}^{2}}
$$

which gives the following formula

$$
\sigma_{N_{t, R d}} \approx \sqrt{f_{y}^{2} \sigma_{A}^{2}+A^{2} \sigma_{f_{y}}^{2}}
$$


In the case of compressed elements, random variables include the cross-sectional area $A$, yield strength $f_{y}$, modulus of elasticity $E$, minimum moment of inertia $J_{m i n}$, and element length $L$. The respective coefficients of variation for the variables listed above are: $6 \%$ for $A, J_{\min }$ and $L$, $8 \%$ for $f_{y}$ and $5 \%$ for $E$ (JCSS, 2001; Gwóźdź and Machowski, 2011). The standard deviation of capacity (2.15) is written as follows

$$
\sigma_{N_{b, R d}} \approx \sqrt{\left(\frac{\partial N_{b, R d}}{\partial \chi}\right)^{2} \sigma_{\chi}^{2}+\left(\frac{\partial N_{b, R d}}{\partial A}\right)^{2} \sigma_{A}^{2}+\left(\frac{\partial N_{b, R d}}{\partial f_{y}}\right)^{2} \sigma_{f_{y}}^{2}}
$$

where $\chi$ is the buckling coefficient, and $\sigma_{\chi}$ is the standard deviation of the buckling coefficient

$$
\sigma_{\chi} \approx \sqrt{\left(\frac{\partial \chi}{\partial A}\right)^{2} \sigma_{A}^{2}+\left(\frac{\partial \chi}{\partial f_{y}}\right)^{2} \sigma_{f_{y}}^{2}+\left(\frac{\partial \chi}{\partial E}\right)^{2} \sigma_{E}^{2}+\left(\frac{\partial \chi}{\partial J_{\min }}\right)^{2} \sigma_{J_{\min }}^{2}+\left(\frac{\partial \chi}{\partial L}\right)^{2} \sigma_{L}^{2}}
$$

\section{Results}

The paper reports the reliability analysis of steel truss towers, in which the system approach was used. Three types of towers with different topology were discussed (Fig. 3). The towers had the same height $(h=16 \mathrm{~m})$ and the same number of segments ( 8 segments), but they differed in geometry and number of elements $l_{e}$. Reliability models were determined for these structures, and next the reliability analysis was carried out. For the wind load, two types of distribution (normal and Gumbel) were used. The impact of connection types and load distributions on the reliability index was analysed. In calculations, to transform from the extreme to normal distribution, two approximation methods (Moments and Point Collocation) were applied. Calculations were carried out using the author-developed programs in the Mathematica environment.

In the first stage, the reliability model was defined. For the first case, tower T1 (Fig. 3a) $\left(l_{e}=40\right)$, the number of KAFMs is 528. They are parallel-serial and serial-parallel mechanisms. The number of causative elements for MCSEs varies from 2 to 9 (Fig. 4). For tower T2 (Fig. 3b) $\left(l_{e}=33\right)$, the number of KAFMs is also 528. All mechanisms are parallel-serial and the number of causative elements for all MCSEs is 2 (Fig. 5). The third case, tower T3 (Fig. 3c) $\left(l_{e}=32\right.$ ) is a statically determinate structure. It is a serial model with 32 causative elements (Fig. 6).

The second stage involved calculation of the reliability index $\beta$. The impacts of the reliability of individual elements and that of the load probability distribution on the reliability index were analysed. In the first case, the reliability index was calculated assuming the same reliability of all elements $\left(R_{i}=R\right)$. Three cases of the reliability of individual elements were considered. The results are shown in Table 1. In the second instance, the towers were designed according to Eurocodes. In calculations, the normal and Gumbel distribution of the wind load were examined. The Method of Moments (MoM) and the Point Collocation Method (PCM) were used for transition from the extreme to normal distribution. The results are shown in Table 2.

Table 1. Reliability index $\beta$ of trusses depending on the reliability of individual elements

\begin{tabular}{|l|c|c|c|}
\hline $\begin{array}{c}\text { Reliability of } \\
\text { individual elements }\end{array}$ & T1 & T2 & T3 \\
\hline \hline$R=0.999$ & 3.881 & 3.275 & 1.859 \\
\hline$R=0.9999$ & 4.884 & 4.405 & 2.727 \\
\hline$R=0.99999$ & 5.724 & 5.317 & 3.414 \\
\hline
\end{tabular}


(a)

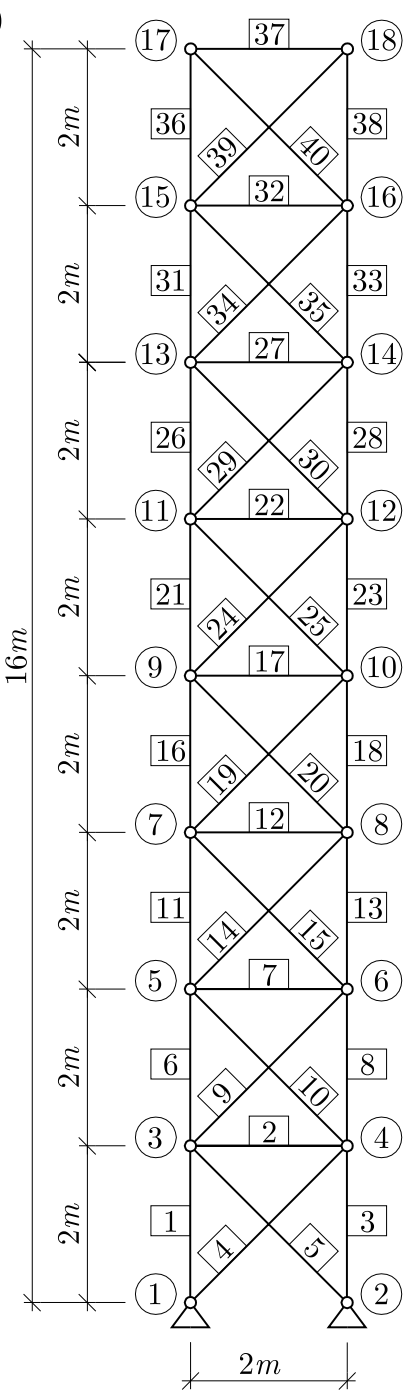

(b)

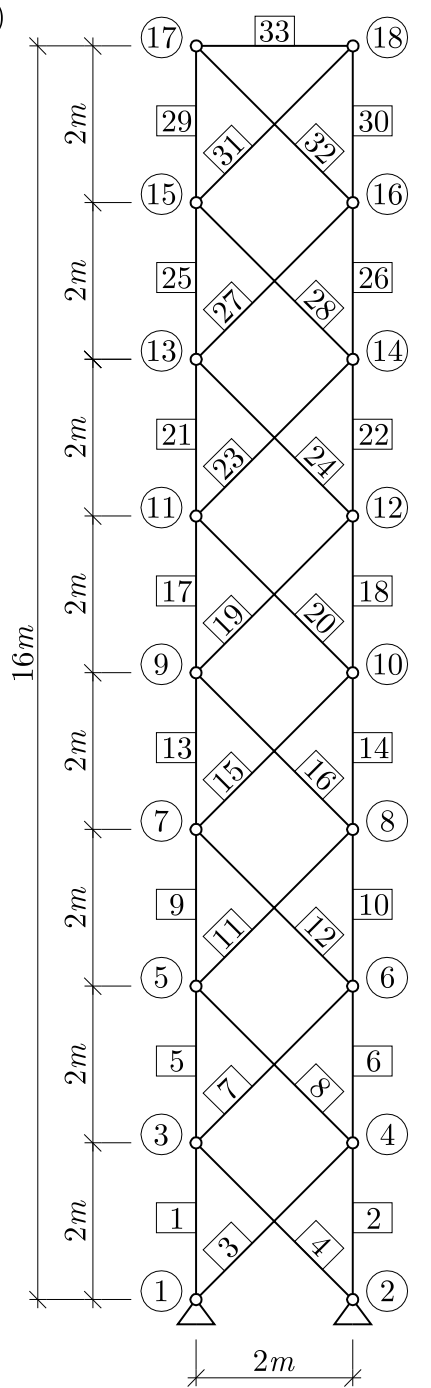

(c)

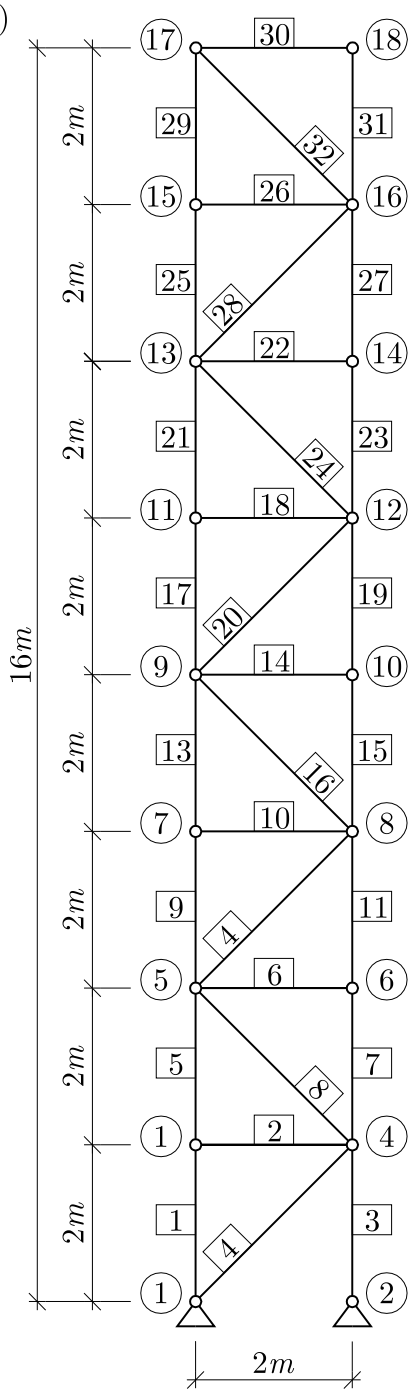

Fig. 3. Truss towers: (a) T1, (b) T2, (c) T3

Table 2. Reliability index $\beta$ of trusses depending on types of load distribution

\begin{tabular}{|c|c|c|c|}
\hline Load distribution $(\mu ; \sigma)$ & $\mathrm{T} 1$ & $\mathrm{~T} 2$ & $\mathrm{~T} 3$ \\
\hline \hline Normal $(27.891 ; 5.578)$ & 3.896 & 3.927 & 2.550 \\
\hline Gumbel $(27.891 ; 5.578) \stackrel{M o M}{\longrightarrow}$ Normal $(31.106 ; 7.154)$ & 3.334 & 3.256 & 2.056 \\
\hline Gumbel $(27.891 ; 5.578) \stackrel{P C M ; k=0.5}{\longrightarrow}$ Normal $(26.974 ; 5.01)$ & 4.083 & 4.146 & 2.710 \\
\hline Gumbel $(27.891 ; 5.578) \stackrel{P C M ; k=0.6}{\longrightarrow}$ Normal $(29.69 ; 5.487)$ & 3.706 & 3.712 & 2.396 \\
\hline Gumbel $(27.891 ; 5.578) \stackrel{P C M ; k=0.75}{\longrightarrow}$ Normal $(35.123 ; 6.412)$ & 2.995 & 2.870 & 1.781 \\
\hline Gumbel $(27.891 ; 5.578) \stackrel{P C M ; k=0.9}{\longrightarrow}$ Normal $(45.494 ; 8.054)$ & 1.800 & 1.314 & 0.661 \\
\hline
\end{tabular}




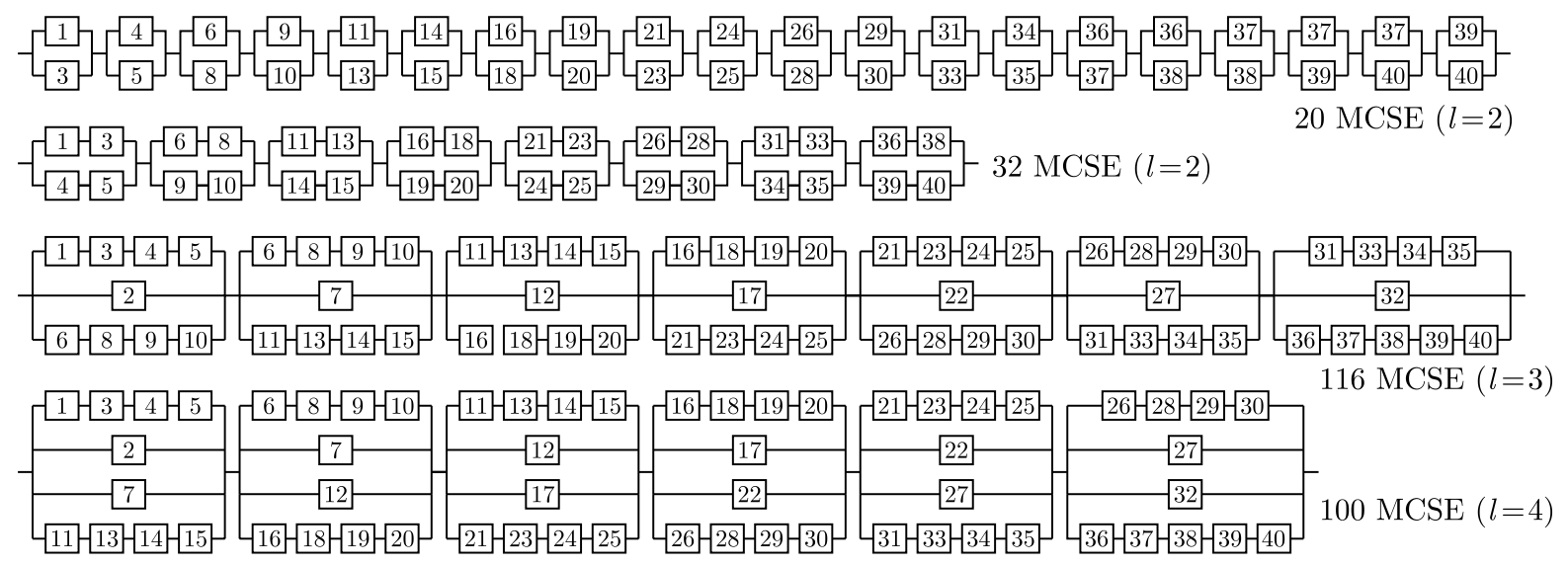

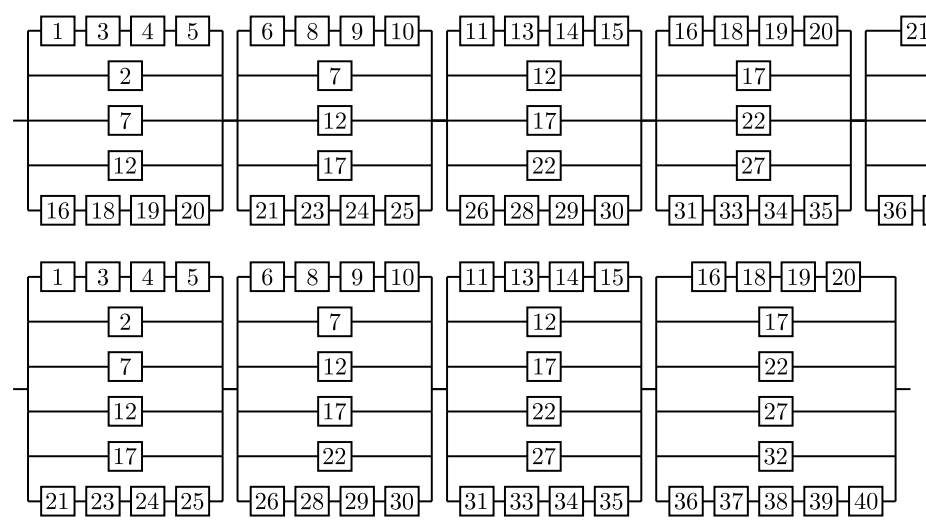

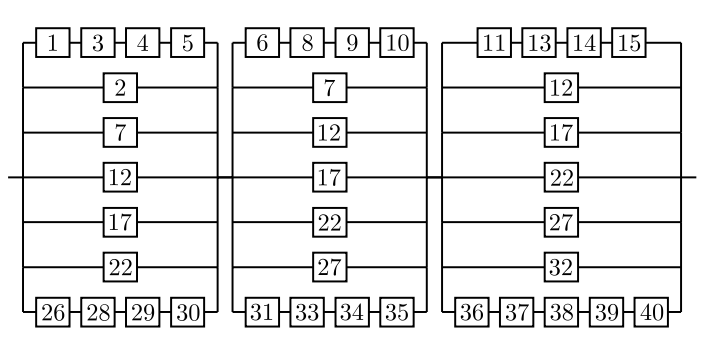

$52 \operatorname{MCSE}(l=7)$

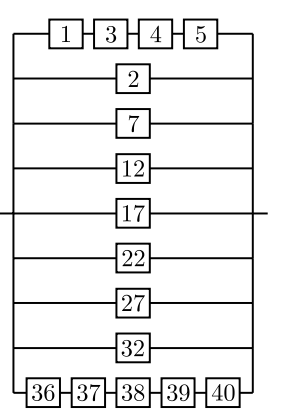

$20 \operatorname{MCSE}(l=9)$

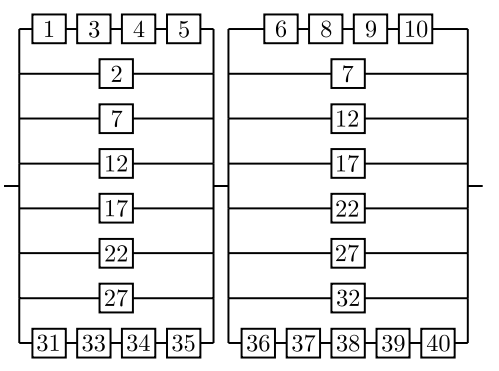

$36 \operatorname{MCSE}(l=8)$

Fig. 4. Kinematically admissible failure mechanisms for tower T1

\section{Conclusions}

The system approach is the most comprehensive reliability analysis because it allows taking into account structural arrangement. With the system approach, two relevant concepts that are closely related and often equated with each other, namely the reliability model and structural safety, can be distinguished.

The reliability model can be characterized by the structure eigenvalue which depends on its geometry and boundary conditions. To define the reliability model, kinematically admissible failure mechanisms (KAFMs) which contain minimal critical sets of elements (MCSEs) should be specified. Exhaustion of the capacity of all elements included in the causative MCSE leads to transformation of the safe structural system into a system of incomplete fixity (mechanism). Tower T3 is statically determinate. The reliability model for this structure is a serial system. It should be noted that for such a system, failure of one element is equivalent to failure of the whole structure. The minimal critical set of elements contains only one element, and the number of kinematically admissible failure mechanisms is equal to the number of causative elements. Consequently, Tower 3 is the most unreliable. An increase in the safety of the serial 


\section{1}

$11-3-4-5-6-7-8-9-10-11-12-13-14-15-16-17-18-19-20-21-22-23-24-25-26-27-28-29-30-31-32-33$ 2

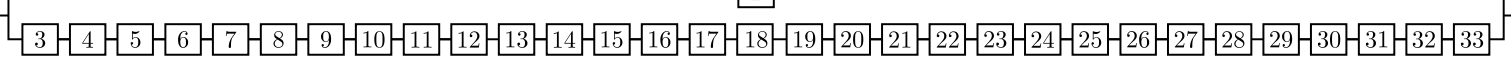

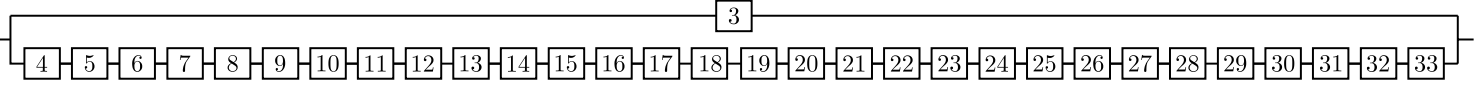

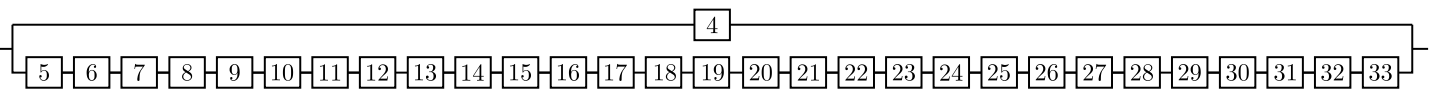

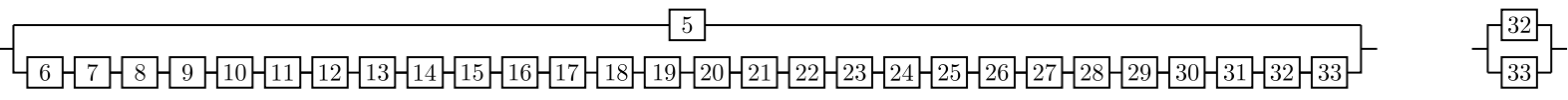

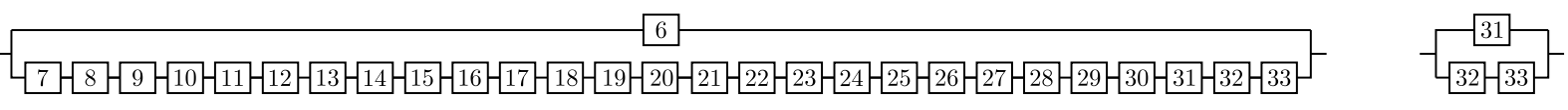
$\sqrt{8-9-10-11-12-13-14-15-16-17-18-\sqrt{19}-20-21-22-23-24-25-26-27-28-29-30-31-32-\sqrt{33}-5}$

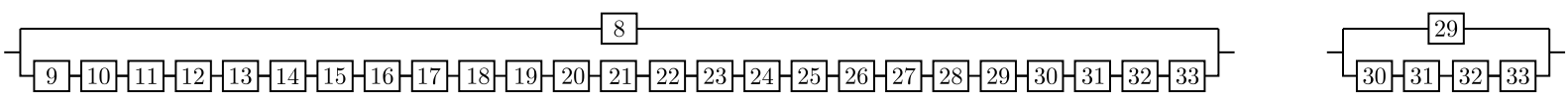

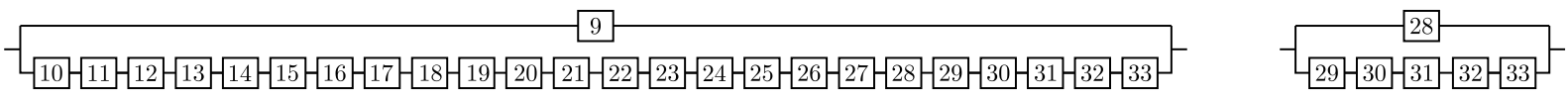

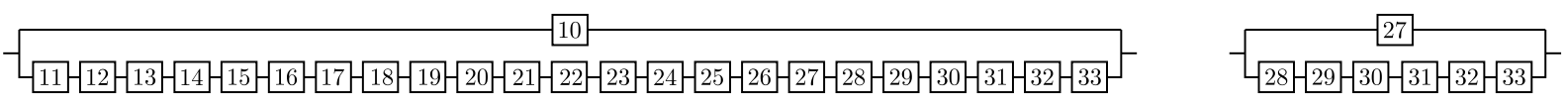

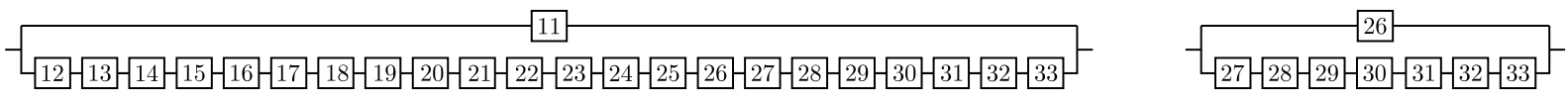
$-\sqrt{13-14-15-\sqrt{16}-17-18-19-20-21-22-\sqrt{23}-24-25-26-27-28-29-30-\sqrt{31}-32-33-5}$

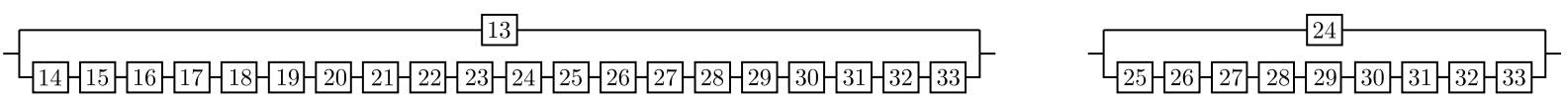

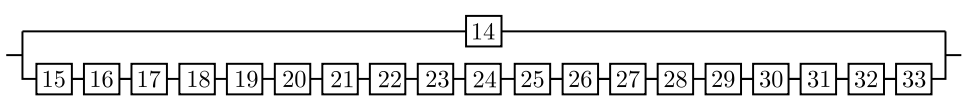
$-16-17-18-19-20-21-22-23-24-25-26-27-28-29-30-\sqrt{31}-32-335-$

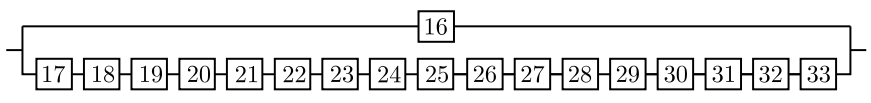
$\sqrt{18-\sqrt{19}-20-21-22-23-24-25-26-27-28-29-30-31-32-\sqrt{33}-}$ $-219-20-21-22-23-24-25-26-27-28-29-30-31-32-335-$ $-24-25-26-27-28-29-30-31-32-33-$ $-\sqrt{23-24-25-26-27-28-29-30-31-32-33-5}$

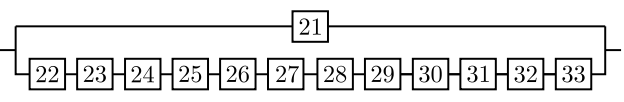
2 19

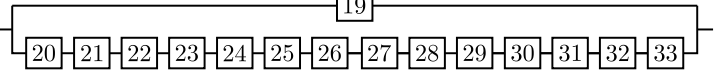
$528 \operatorname{MCSE}(l=2)$

Fig. 5. Kinematically admissible failure mechanisms for tower T2

$-1,2-3,4-5,6-7,8-9-10-11-12-13-14-15-16-$ $-17-18-19-20-21-22-23-24-25-26-27-28-29-30-31-32-$

Fig. 6. Kinematically admissible failure mechanisms for tower T3 
system can be obtained by two means, namely by increasing the safety of the weakest element of the system, or by limiting the number of elements that are linked in series. In the paper, Table 1 shows the increase in the reliability of the structure along with the increase in the reliability of the elements. Reliability of individual elements change from 0.999 to 0.99999 . We assume here that the reliability of all components is the same. Towers $\mathrm{T} 2$ and $\mathrm{T} 1$ are statically indeterminate structures. These structures correspond to the mixed reliability model. Statically indeterminate structures have many kinematically admissible failure mechanisms, in which common elements are found. The same elements are components of more than one critical set. Then, estimation of the safety of the structure is a difficult task that gets even more complex as the numbers of MCSE and common causative elements increase. As a result, simplified estimation, i.e. the lower estimate of the structure safety is applied. That involves separation of the minimal critical sets of elements that have common causative elements. After MCSEs are separated, it can be assumed that all kinematically admissible failure mechanisms defined for a given structure are connected to one another in series. In the study, the assumption holds that MCSEs are unseparated. The reliability models of towers $\mathrm{T} 2$ and $\mathrm{T} 1$ differ fundamentally. The reliability model of tower $\mathrm{T} 2$ contains 528 KAFMs. All mechanisms are parallel-serial, and the number of causative elements for all MCSEs is 2. The reliability model of the tower T1 contain also 528 KAFMs, but the number of causative elements for MCSEs ranges from 2 to 9 . They are parallel-serial and serial-parallel mechanisms. The failure of such a structure is definitely less likely. Tower T1 is the most reliable structure.

The wind load probability distribution has significant influence on the reliability index. In the paper, two types of load distribution (normal and Gumbel) were applied. The method of the reliability analysis selected for the paper required that the normal distribution should be used for all random variables. That made it necessary to transform the Gumbel distribution into the normal distribution. To achieve that, two approximation methods, namely the Method of Moments and the Point Collocation Method were used. The Method of Moments is simpler and relatively fast allows one to obtain satisfactory results. After transformation of the Gumbel distribution to the normal distribution the reliability index was reduced to $24 \%$. The Point Collocation Method is more accurate but more computationally complex and, therefore, also more time-consuming. In this method, the most important issue is the choice of the parameter $k$. In the paper, calculations were performed for four cases of the parameter $k(k: 0.5,0.6,0.75,0.9)$. In the case of $k=0.5$, the reliability index is overestimated compared to values obtained for the normal distribution, whereas in the case of $k=0.9$ is significantly lower (to $286 \%$ ). Much more reliable results were obtained for values $k=0.6$ and $k=0.75$. The advantage of the Point Collocation Method is the possibility of choosing the value of the parameter $k$ depending on the design situation (uncertainty of the load model, structures with unusual loads). It allows obtaining the adequate safety margin.

\section{References}

1. Biegus A., 1977, Probabilistic Analysis of Steel Structures (in Polish), PWN, Warsaw-Wroclaw

2. BŁaszczyński T., SumigaŁa M., Polus Ł., 2014, Analysis of damage of two steel antenna towers with repair proposal, Materiaty Budowlane, 5, 48-50, ISSN 0137-2971

3. Boøotin W.W., 1968, Statistical Methods in Structural Mechanics, Holden Day, San Francisco

4. Davies D.K., 2011, North American Tower Failures: Causes and Cures, Evansville, USA

5. DudzIK A., 2017, Reliability assessment of steel-aluminium lattice tower, IOP Conference Series: Materials Science and Engineering, $\mathbf{2 4 5}$

6. GwóźDź M., Machowski A., 2011, Selected Studies and Calculations of Building Structures with Probabilistic Methods (in Polish), Oficyna Wydawnicza Politechniki Krakowskiej, Kraków, Poland 
7. JCSS, Probabilistic Model Code, Joint Committee of Structural Safety, 2001

8. KAMiŃski M., SzAFran J., 2010, On computer modelling of reliability of steel telecommunication towers, Zeszyty Naukowe, Budownictwo, Politechnika Eódzka, 62, 51-66

9. KŁosowska J., Obara P., Turant J., 2017, Kinematically admissible failure mechanisms for plane trusses, IOP Conference Series: Materials Science and Engineering, 245

10. Kubicka K., Obara P., Radoń U., Szaniec W., 2019, Assessment of steel truss fire safety in terms of the system reliability analysis, Archives of Civil and Mechanical Engineering, 19, 2, 417-427

11. Kubicka K., Radoń U., 2015, Proposal for the assessment of steel truss reliability under fire conditions, Archives of Civil Engineering, 61, 4, 141-154

12. Mochocki W., Obara P., Radoń U., 2018a, System-reliability analysis of steel truss towers, MATEC Web of Conferences, 219, DOI: 10.1051/matecconf/201821902001

13. Mochocki W., Obara P., Turant J., 2018b, Influence of truss topology on reliability index, IOP Conference Series: Materials Science and Engineering, 471, DOI: 10.1088/1757$899 \mathrm{X} / 471 / 5 / 052061$

14. Mochocki W., Radoń U., 2019, Analysis of basic failure scenarios of a truss tower in a probabilistic approach, Applied Sciences-Basel, 9, 13, 2662

15. Murzewski J., 1989, Reliability of Engineering Structures (in Polish), Arkady, Warsaw

16. Murzewski J., 1999, Fundamentals of Design and Structural Reliability (in Polish), Cracow University of Technology, Cracow

17. NowaK A.S., Collins K.R., 2000, Reliability of Structures, McGraw-Hill Companies Inc., A Higher Education Division, Boston

18. Paczkowska T., Paczkowski W., 2013, A designer mistake as a reason for the threat of loosing the bearing capacity by a steel tower, Przeglad Budowlany, 12, 52-56

19. Park S., Choi S., Sikorsky C., Stubbs N., 2004, Efficient method for calculation of system reliability of a complex structure, International Journal of Solids and Structures, 41, 5035-5050

20. PN-EN 1990:2004, Eurocode: Basis of structural design

21. PN-EN 1991-1-4, Eurocode 1: Actions on structures. General actions. Wind actions

22. PN-EN 1993-1-1, Eurocode 3: Design of steel structures. Part 1-1: General rules and rules for buildings

23. PN-EN 1993-3-1, Eurocode 3: Design of steel structures. Part 3-1: Towers, masts and chimneys Towers and masts

24. Rackwitz R., Flessler B., 1978, Structural reliability under combined random load sequences, Computers and Structures, 9, 489-494

25. Rykaluk K., 2005, Steel Structures. Chimneys, Towers, Masts (in Polish), Oficyna Wydawnicza Politechniki Wrocławskiej, Wrocław, Poland

26. Skwarek M., Hulimka J., 2011, Is the steel latticed tower for telecommunication threatened failure? About estimate of load capacity of latticed towers in diagnostics of constructions (in Polish), Proceedings of the 25th Conference on Structural Failures, Międzyzdroje, Poland

27. Skwarek M., Tomska D., Hulimka J., KozŁowski M., 2013, Some problems with steel latticed telecommunication towers structure strengthening (in Polish), Proceedings of the 26th Conference on Structural Failures, Szczecin-Międzyzdroje

28. Śniady P., 2000, Fundamentals of Stochastic Structural Dynamics (in Polish), Oficyna Wydawnicza Politechniki Wrocławskiej, Wrocław, Poland

29. Thoft-Christensen P., Baker M., 1982, Structural Reliability Theory and its Applications, Springer-Verlag, Berlin Heidelberg, New York 
30. Winkelmann K., OzięBeo M., 2015, Reliability assessment of truss towers using Monte Carlo Method, PEM and RSM, Proceedings of the PCM-CMM-2015 - 3rd Polish Congress of Mechanics and 21st Computer Methods in Mechanics, Gdańsk, Poland

31. Woliński S., Wróbel K., 2001, Reliability of Building Structures (in Polish), Oficyna Politechniki Rzeszowskiej, Rzeszów, Poland

Manuscript received November 28, 2019; accepted for print January 23, 2020 